\title{
Language Sociality and Its Enlightenment on Foreign Language Teaching
}

\author{
Guijie Liu \\ School of Foreign Studies, North China University of Water Resources and Electric Power, Zhengzhou, China
}

\begin{abstract}
Language is a unique tool used to express meaning and exchange ideas while sociality is a basic attribute to it. The language sociality lies in that languages exist in social activities and evolve simultaneously. Cognition of language sociality, to some extent, has an implicit or explicit influence on foreign language teaching (FLT). As one social behavior affected by the environment around, language is interfered with social, cognitional and cultural factors, which is evidently reflected in difficulties in FLT. To apply language sociality into FLT and improve the validity and reliability in the process, the following aspects need to be considered and innovated: the curriculum, process of teaching, quality of teachers, involvement of students as well as research on cultural fusion.
\end{abstract}

Index Terms—language sociality, FLT, relationship, enlightenment

\section{INTRODUCTION}

Language is a unique tool used to express meanings and exchange ideas. Language, an important tool for building and creating society, is also the product of a certain society. Yu Genyuan (2010) holds that language belongs to the common behavior of all members of society. Concerning foreign language teaching (FLT), talks and discussions on the reform and innovation have always become the focus among researchers in educational circles. As a language, its main purpose is to ensure communication with each other, and as a foreign language (English as the case study hereafter), it is a tool generally used to carry out interlingual or cross-cultural communication. However, the reliability and validity of traditional teaching model deviates from the original function and purpose of a language. It is no denying that when researchers consider appropriate research methods, sometimes the ethical concerns, dilemmas and conflicts in scientific research will bring them to a standstill (Seidman, 2006). Shu Dingfang, the famous educationist and linguist in China, states that the theoretical research of foreign language classroom teaching in China is weak, and there has been a lack of scientific, reasonable and effective evaluation criteria for foreign language classroom teaching. In actual classroom teaching, there are still some problems, such as the ambiguity of teachers' teaching objectives, the incompatibility of teaching content with students' needs, the lack of innovation in teaching process, and the lack of cohesion between classroom teaching and extracurricular learning (2014). Hence, the voice of "changing the mode of foreign language teaching and promoting its effect" has gradually become the common understanding as well as consensus of great scholars, teachers and other participants in the educational field. Improving the comprehensive ability of listening, speaking, reading, writing and translating of foreign language learners is clearly the task in teaching practice in the new era.

Due to the difference and lag in the cognition of language, the foreign language teaching in China has been focusing on the study of language forms, such as grammatical structure, spelling, and misuse of words, etc. for a long time, regarding phonetics, grammar and lexicon as the sole element of foreign language teaching, and ignoring the positive influence of the culture attached to language on the acquisition and intercommunication of skills. In reality, language is a kind of social phenomenon, including the structure of language and social environment as well. When languages are considered in a society-related environment, the sociality is involved without exception. On the basis of the analysis of the sociality of language, this paper puts forward some determinant factors, such as cognitional, social, cultural and inter-linguistic differences, in language teaching, so as to provide a definite guiding value for the study and the teaching of a foreign language.

\section{THEORETICAL ANALYSIS}

Specifically, language is shared not by an individual, but by all members of society and it is a system of social meaning, which reflects and constructs social reality and is the foundation of human society (Hu \& Yu, 2015). Besides, it is the means for thinking and communicating but not a pure physiological phenomenon or psychological activity. In such a sense, language is a special social phenomenon but not a common one. Edward Sapir(2004), the linguist, stated in his Language: An Introduction to the Study of Speech that Language is a particular expression of thought and culture which may be defined as what a society does and thinks. The message Sapir is delivering here is that language should be applied and used in a social environment. Speakers of one language belong to the same kind of people (or many kinds of people), that is to say, a group which is separate from other groups because of its different conditions. language 
cannot exist without culture, and cannot exist without the practices and beliefs that continue to be inherited by society, and the totality of these practices and beliefs determines the nature of our lives: the sociality. When it comes to the relationship between language sociality and language teaching, there are two different concepts: one is to regard language teaching as a combination of phonetics, pragmatics and lexicon, or just as a sign system; the other is to regard it as closely related to culture. It is indisputable that the use of language and the study of language are inseparable from the social environment.

Thus, the second concept is acceptable and applicable at present, which highlights the fact that language teaching is involved with a number of factors, not merely with language itself. The educationist James E. Alatis (2012) adheres to the fact that language teaching and its process is a complexity made up of linguistics, sociology, pedagogy and culturology. In other words, FLT is supposed to be combined with linguistic, social, cultural and educational factors. As can be seen from the above, language is a complex and comprehensive system which includes anthropology, sociology, sociolinguistics and other disciplines. Thus, the sociality of language can be clearly demonstrated in the theoretical aspect.

The sociability of language is also manifested as interlingual cultural interference. Teachers should all have cultural awareness and cultural sensitivity when carrying out their teaching activities. Elvin, a researcher specialized in teaching methodology and conceptualization, reminds teachers that cultural interference actually creates many difficulties and conflicts for teaching, whether teachers are aware of it or not. The reflection of the learning layer is the anamorphosis in the learning process of college students. As Marx said, "even when I am engaged in a scientific activity, that is, in a kind of direct intercourse with others which I can only on very rare occasions, I am social, for I act as a man; Not only are the materials necessary for my activities, but even the language which the thinker uses for activities is itself given to me as a product of society, and my own existence is a social activity." However, in most teaching practices, students are regarded as individuals abstractly without concern for specific social survival circumstances and personality differences. Language teaching is actively generated in the interaction with other social practice activities. Therefore, sociality is the essential attribute of teaching activities.

To be true, sociality of language has long been reflected in teaching practices. The only problem is that few has put emphasis on it, particularly in FLT. The following examples can be the demonstration.

一个和尚挑水吃, 两个和尚抬水吃, 三个和尚没水吃。

Translated version: One boy is a boy, two boys half a boy, three boys no boy.

腊月二十三灶王爷上天, 后台封戏, 要等年初一开戏。

Translated version: On the twenty third of the twelfth lunar month, the kitchen god went up to heaven...

As a culture-loaded and socially manifested character, “和尚” is full of traditional Chinese feature, and there is no equivalent in English language. Thus, the English version "boy" can not totally convey the cultural implication in Chinese. In the second sentence, the western world tends to misunderstand or even cannot accept “灶王爷”. To make it clear or acceptable by the westerners, the English version has been translated into “kitchen god”. Obviously, “和尚”, “灶 王爷”, "boy" and "kitchen god" will not be understandable or communicative if confined to the language itself and do not take into account the underlying cultural differences, of which sociality of language is the most effective way to tackle. Besides, the differences between target language and the source language lie in the sociality of languages. Under such a circumstance, the following three relations should be successfully addressed: language and culture, ability between language and communication, and the integration and implantation of cultural elements in language teaching. As we know, one of the key tasks of sociolinguistics is to deal with contradictory relation between linguistic form and social constraint, as well as relation between interlingual difference and linguistic comprehension.

From what has been discussed above, we may draw the conclusion that sociality of a language can be vividly expressed and exposed implicitly and explicitly. As for teaching practice, it is the manifestation in the explicit way. "About 800 years ago, Oxford University was founded, and then 100 years ago, Harvard University was founded, and then Jingshi Teaching House was built in 1898 in China which was the so-called university in modern China " (Liu Guijie, 2010). We may safely say that all these universities are built to cater for economic, a social and cultural development. The author here intends to make it clear that education, in any sense, is a social practice with clear intention. Teaching practice and other social activities are interactions in which the original purpose of education itself comes to a reality.

In a nutshell, sociality is the fundamental factor of teaching practice and curriculum can be regarded as the implicit representation. Concept of curriculum, teaching materials, teachers' lead-in methodology and students' understanding towards what they learned are all involved in a scientific process, and at the same time, in a social process with complicated parameters. So, sociality of language can not be ignored in teaching practice, particularly in FLT. Reasons for the low validity and reliability in China in FLT are mentioned above. Based on the above discussion, the following will focus on how to innovate and reform in FLT practice.

\section{ENLIGHTENMENT IN FLT}

The sociality of language implicitly expresses that the process of foreign language teaching cannot be a vacuum and must be restricted by the internal and external elements of a language. In the specific teaching practice, due attention 
should be given to these three elements: language, language learners and language environment. Language environment determines the validity and breadth of learners. Language learners are supposed to be active information receivers, while language transmission (informational or cultural transmission) evaluates and demonstrates teachers' professional standards and ethics. The above elements are mutually conditioned relations. Any of these factors may result in the failure of teaching, that is, the failure of informational or cultural transmission. The correct cognition of the sociality of a language is helpful to foreign language teaching in the following aspects.

\section{A. Curriculum of Foreign Languages}

The cognitive reflection of language sociality is that in addition to linguistics, sociolinguistics, pedagogy, psychology and other major disciplines, when conditions permit, sociology, anthropology and other marginal disciplines should be added in time. That is to say, Teaching should not simply stay on the students' existing learning ability, which will restrict the development of students, especially the students with outstanding learning ability; but teaching can not go beyond the students' current abilities without limit, otherwise the teaching process will be a meaningless dialogue, and students will not be able to carry out effective learning.

At the same time, it should be noted that language is influenced by social and interlingual environment, cultural background and customs. In teaching, the use of foreign original textbooks and an increase use of authentic material should be encouraged. The advantage of "authentic material" is that it reflects the differences in social factors, such as identity, close relationship, communication occasion, and culture and habits often are reflected in the annotations. According to Vygotsky's theory of the zone of proximal development, we understand that the courses offered by schools must not only be based on the existing foundation of students, but also have certain difficulty and height. This does not only ensure that students learn knowledge in practice, but also promote the improvement of students' ability. It also respects the individual differences of students to a greater extent.

In fact, the relation between Linguistics and foreign language teaching has been misunderstood for a long time. While they are two different disciplines, and are closely related and interdependent. This fact also reflects the common trend of academic development in today's world: integration, interdisciplinary, integration of theory and practice. Besides the traditional literary knowledge and the ability of listening, speaking, reading and writing, foreign language majors and translation majors should master many other kinds of knowledge, such as philosophy, Chinese, culture, computer application and so on. Mr. Guozhang Xu (1991) pointed out that "Language is a unique symbol system of human beings. When it acts on the relationship between human beings, it is an intermediary to express mutual reaction; when it acts on the relationship between human beings and the objective world, it is a tool to recognize things; when it acts on culture, it is the carrier and container of cultural information."

\section{B. Students'Involvement}

The difference between the target language and the native language often becomes an obstacle to oral and written communication. Language sociality requires the process in FLT highlights students' cross-cultural and inter-lingual awareness. Teaching is a dynamic process, which requires communication and experience between teachers and students. Participation is the core of modern teaching activities. Subject participation is restricted by factors such as teachers' accomplishment, teacher-student relationship, emotional limitation, situational setting and technical resources (Zhao Dongsheng, 2015). Students should be guided towards paying attention to the accumulation of a cultural background, social customs and social relations when reading literary works and foreign newspapers. Moreover, autonomous learning should be the main way, and learners' attitudes and sources of autonomous learning materials should be regularly evaluated and confirmed.

With a correct understanding of the sociality of language, the requirements for teachers' quality have also been improved. In the process of teaching, teachers should not only pay attention to the accuracy of language forms, but also pay attention to the proper use of language and strive to make students gradually acquire "sociolingustic awareness".

Since we have a clear understanding of sociality of language in FLT, interaction and experience may be one of the ways for students' involvement. Culture is a dynamic and vivid phenomenon. Every day people participate in the practice of culture in a common way of life, while experiencing and creating their history or civilization. The author here wants to emphasize people's participation in cultural experience. Cultural teaching should use experiential education and take "cultural experience" as the core concept of cultural teaching theory. To help students understand culture, we can start with three frameworks: the wireless cycle of cultural knowledge, cultural experience and experiential learning. This is actually a series of methods, through a circular process of cultural learning. This process includes four steps: participation (direct or indirect), description (understanding content), explanation (understanding reason), and response (self-understanding). This method aims at organizing students to participate in language practice activities in order to deepen the understanding of foreign culture. In the process of experiencing culture, learners can construct rules of cultural behavior, acquire cultural information, and form awareness of cultural understanding and personal response. The forms of cultural experience activities can be diversified. They can be high participation in theatrical performances and dialogues, as well as watching related movies, reading literary works, observing pictures and other activities such as listening, speaking, reading and writing.

In FLT in modern era, Language teachers should help students understand the differences between the world and Chinese and Western cultures and broaden their horizons. It also helps students to create contact with, understand and 
learn the knowledge of intercultural communication when they begin to learn English, and lays a good foundation for them to improve their sensitivity, discrimination and intercultural communicative competence in further learning.

\section{Innovative Teaching Method}

Today's language teaching is more interactive and imaginative than any time in history (Zhao Yang, 2017).In order to improve validity and reliability in FLT, it is of necessity to make full use of multimedia, pictures, slides, movies and other visual teaching aids to enrich students' foreign cultural complex. Tolstoy once said, "Knowledge is real knowledge only when it is acquired by positive thinking." The use of multimedia and other auxiliary means. It can give full play to students' active thinking, but also provide students with a comprehensive and creative after-class practice environment, so that the rich amount of information in the classroom can be internalized as part of students' knowledge structure.

According to the theory of cultural transfer, if the learner's language culture differs greatly from the target language culture, the learner will keep a distance with the target language in social and psychological aspects. Foreign teachers can bridge the gap between the native language and the target language. As the imparter of foreign culture, foreign teachers have unique conditions in cross-cultural cultivation and awareness. The learners' interest is abundant, and the transmitter can handle it freely. Naturally, the phenomena of cultural conflict and shock are solved.

In a sense, we are supposed to continue to advocate task-based teaching, and even try content-based language teaching, in order to create a social practice activity system in the classroom; in Task-based teaching, learn to use the various elements of activity system-themes, objectives, tools, rules, etc. to organize and operate tasks, strengthen the mediating role of teachers, and improve the efficiency of task operation. At the same time, we should pay attention to not only students' language development, but also their language socialization and self-identity development. As far as second language learners are concerned, the peculiarity of classroom mediation lies in the following aspects: first, providing and optimizing language resources, such as choosing appropriate language materials for students; acting as a model or model for the use of the target language in classroom communication; creating opportunities for students to use the language and assisting them when they have difficulties in understanding or expressing the target language. Secondly, the rational allocation of language activities with emphasis on form and meaning, such as: when setting up exercises, consider the proportion of balanced input and output. Thirdly, to create a supportive emotional environment, especially to help reduce the anxiety and tension peculiar to second language learners.

Taking relationship between language and thinking into consideration, we may safely draw the conclusion that diversity of language and culture cannot be ignored. Language and thinking have two-way interaction. Thinking determines language. Language in turn influences thinking. Specific ethnic groups have formed a relatively fixed group thinking tradition based on long-term and stable co-production and life. Therefore, cultural relativity brings about the relative stability and pluralism of language, which enlightens us that in foreign language teaching, we must pay attention to comparing the differences of thinking characteristics between different countries and nations, and then accurately grasp the differences of cross-regional cultural characteristics, so as to effectively enhance students' interest, clear up the obstacles of context and background for language learning itself, and eliminate the despair of literary meaning and rote memorization. Back-leaning also provides understanding and supporting factors for cross-cultural communication. It is suggested that language learning should establish an organic and unified relationship with the popularization of human geography and physical geography, achieve classroom integration and knowledge linkage, and enhance a three-dimensional and appealing teaching.

\section{Emphasis on Inter-cultural Differences and Inter-lingual Research}

The sociality of language is accompanied by the difference of language. Therefore, it is difficult for cultural guidance to be realized in foreign language classroom teaching. Teachers are required to pay attention to the transplantation and innovation of culture and strengthen understanding and research. However, it is not necessary and should not be blindly imitated and used, nor should there be cultural discrimination. We oppose cultural hegemony and isolation. Educators' research results should be applied to teaching in real time to serve the goal of language teaching.

"The differences between China and the West are mainly manifested in culture and thinking." Cultural studies guided by social theories. If they had been forward-looking rather than lagging behind reality, the translation of mascots for the 2008 Olympic Games will not cause so much controversy, "Friendlies" will be replaced by "Fuwa". At the same time, Li Ning's slogan "Anything is possible" and Adidas's slogan "Impossible is nothing" were naturally accepted.

Chinese is made up of a variety of Chinese characters and English is also made up of various English vocabularies. Therefore, in College English teaching in China, teachers should start with English vocabulary, analyze the different uses of the same vocabulary and its symbolic meanings in different countries, and let students understand and grasp the core of vocabulary according to the different meanings of the same vocabulary and its different contexts. In the usage, we should fully grasp the use of vocabulary in different contexts to avoid embarrassing problems caused by misunderstanding or ignorance. For example, the word "dragon" symbolizes the supreme right in China, while in some European and American countries, "dragon" symbolizes the devil. It can be seen that there are obvious differences in the meaning expressed by the same vocabulary in different countries. Therefore, it is far from enough for teachers to improve students' English proficiency in an all-round way. Besides, students need to understand each other. Understanding of national culture, in some sense, embodies students' cultural literacy. 
Teachers should interpret English textbooks in detail. First of all, they should clarify the cultures of different countries so as to transmit the cultural knowledge of different countries to students and enable them to fully grasp the cultural information in the textbooks. For example, when explaining the content of "thanks-giving day", teachers should first collect all kinds of literature and information resources, fully understand the historical and cultural origins of the festival, and then tell the students about the origin of Thanksgiving Day in class, as well as the development process abroad, so that students can learn English under the premise of mastering English culture. Textbooks are not only carriers of culture, but also ways for students to learn. Therefore, in English teaching, we should first let students understand foreign cultural knowledge and improve their cultural literacy. On this basis, we should strengthen the interpretation of textbooks and improve students' English level.

\section{E. Guidance of Current Educational Theories}

Language acquisition is inseparable from the communication between people and people, people and society. When people are embedded in the same social system, each person will construct characteristics for the whole system through his own experience, and at the same time generate a language learning occasion with the help of this system. According to some researchers, society and people interact with each other, so researchers put forward the sociocultural theory of second language acquisition, which regards social interaction as a model of language acquisition. The learners are no longer regarded as the receivers of mechanical processing of language input, but as the actors of their own language learning. They gradually learn language through the above models and methods for their own use in social interaction.

Considering the fact that globalization, post-modernism and internationalization are warming up and profoundly affecting the trend of social development, foreign language education has become an invisible yardstick of the most important social resources and cultural soft power of a country. Foreign language education has naturally become the bridgehead of communication and exchange between states, nations and cultures. It also bears the important mission of promoting the dissemination of traditional Chinese cultural values. Moreover, it plays an important role in maintaining national ideology, national identity, coordinating the harmonious development of society and achieving international understanding. As we all know, education is a spiritual purified land to relay knowledge, pursue truth and defend justice. However, in the current cultural logic, education gradually loses its inherent essence and ideal. Foreign language education is also "alienating" its true face. It is gradually falling into the utilitarian mud pit created by pursuing the value of educational tools. As is accepted, to ensure that learners spend their time and effort meaningfully and for maximum benefits, there must be a plan for them to work according to specific learning targets which are geared towards the aims of the curriculum. All learning and assessment activities, including the contents and strategies for such activities, should be geared towards maximum learning effectiveness for achieving the learning targets. In order to win dignity in college foreign language education, we must pay close attention to the construction and combining of theories, devote ourselves to the exploration of the laws of foreign language education and the establishment of teaching theories, attach importance to the relationship between theory and practice, find out the discomfort and distance between theory and practice, and pay attention to the complexity and uncertainty in the field of practice, so as to standardize the behavior and uncertainty in educational practice. Anyhow, as is stated by Gao Wei (2018), constructing educational philosophy is a long historical process. It is the mission and rational consciousness of educational philosophers who are supposed to carry out academic research and ideological creation.

\section{CONCLUSION}

In today's English teaching, we believe that we should aim at cultivating students' practical language application, overcome learning and teaching obstacles caused by differences in cognition, social culture and subject groups, constantly broaden and expand students' knowledge of various cultural backgrounds, and conduct intercultural communication training in a suitable, timely and appropriate manner, so as to improve teaching efficiency and cultivate students' consciousness of intercultural communication. At the same time, the problems related to the reform of education system that need to be solved urgently will also be successfully and satisfactorily addressed.

It is true that the change from teacher-oriented to student-oriented and from translation-oriented to immersion-oriented will be the result of the renewal of educational theory. The introduction of linguistic social cognitive theory will inevitably provide a new perspective and teaching method for foreign language teaching, thus enriching the research content of foreign language teaching and deepening our understanding of this issue. The perspective of language learning is multidimensional. If we compare the sociocultural perspective with other perspectives, such as psycholinguistic perspective, although the two perspectives have different cognitive perspectives, they are not necessarily contradictory in practical application, but complementary or even compatible.

Language, as a unique thinking carrier, communicative information symbol system and external behavioral expression, has multiple social and natural attributes. It belongs to cultural phenomena and serves as a direct observation basis to characterize specific national cultural traditions, and in turn promotes cross-regional and inter-generational cultural transmission and inheritance. Consistent with general cultural phenomena, the production and expression of language is not disorderly, but based on the specific thinking function of human beings, which is restricted by specific production and living practices. It can be said that specific production and living patterns directly determine the types and characteristics of thinking patterns, and reinforce them in repeated practice, thus prone to 
"stereotyped thinking". Along with it, linguistic and cultural achievements such as vocabulary and grammar, which are based on service-specific thinking expression and collaborative objective needs, will show the characteristics of diversification and individualization.

\section{REFERENCES}

[1] Ancker, William P. (2012). The psychic rewards of teaching: An interview with James E. Alatis. English Teaching Forum, Vol.50, No.1, 20-27.

[2] Gao, Wei. (2018). Constructing the philosophy of education with Chinese scene. Educational Research, 9, 52-58+88.

[3] Hu wenhui \& Yu zhangya. (2015). Philosophical foundation of language evaluation theory. Jiangxi Social Sciences. 3, 31-35.

[4] Liu, Guijie. (2010). Enlightenment of effect of linguistic sociality on foreign language teaching. Journal of Huaihai Institute of Technology, 3, 83-85.

[5] Sapir, Edward. (2004). Language: An introduction to the study of speech. New York: Dover Publications.

[6] Seidman, I. (2006). Interviewing as qualitative research: A guide for researchers in education and the social sciences. New York and London: Teachers College Press.

[7] Shu, Dingfang. (2014). Problems and research topics in foreign language classroom teaching. Foreign Language Teaching and Research, 46 (3), 446-455.

[8] Xu, Guozhang. (1991). On languages by Xu Guozhang. Shanghai: Foreign Languages Teaching and Research Press.

[9] Yu, Genyuan. (2010). Some hypotheses on linguistic mechanisms. Ludong University Journal (Philosophy and Social Science Edition), 5, 47-51.

[10] Zhao, Dongsheng. (2015). On students' participation in effective foreign language teaching. Journal of Teaching and Management, 11, 90-92.

[11] Zhao, Yang. (2017). The evolution of foreign language teaching method: From method to principle. Journal of International Chinese Teaching, 1, 20-22.

Guijie Liu was born in Shandong Province, China in 1979. He finished his MA in Linguistics and Applied Linguistics (Translation) in Shannxi Normal University, China in 2009. He is a lecturer at the School of Foreign Studies, North China University of Water Resources and Electric Power, and he is currently studying for a Ph.D degree at SISU (Shanghai International Studies University). His major research interests are in Comparative Literature and Cross-cultural Studies as well as Teaching Methodology. 